\title{
不恽物をドーブしたマンガン酸化物の磁化挙動シミュレーション
}

\section{Simulation of Magnetization Behavior in Impurity Doped Manganites}

\author{
中園晋輔・小野寛太・尾鴄正治 \\ 東京大学大学院工学系研究科, 東京都文京区本楖 7-3-1 ₹113-8656 \\ S. Nakazono, K. Ono, and M. Oshima \\ School of Engineering University of Tokyo, 7-3-1 Hongo, Bunkyo-ku, Tokyo 113-8656 \\ (1999 年 10 月 28 日受理, 2000 年 1 月 25 日採録)
}

We carried out three-dimensional Ising model calculation of Cr-doped manganites $\mathrm{LaCrxMn1-x}_{3}$, using the Monte Carlo method, to study their magnetization behavior. The magnetic interaction between $\mathrm{Mn}^{3+}$ and $\mathrm{Cr}^{3+}$ is generally thought to be ferromagnetic, in accordance with the Kanamori-Goodenough rules, whereas our calculation suggests that the magnetic interaction should be antiferromagnetic. These calculation results agree well with the experimental results.

Key words: superexchange interaction, 3D Ising model, Monte Carlo method

\section{1.はじめに}

ペロブスカイト構造をもつマンカンン酸化物は, 近年超巨 大磁気抵抗 (CMR) が観測されたことで非常に注目を集め ている物質群である。

最近はMnサイトを他の遷移金属イオンで置換したとき の遷移金属不純物の効果が注目を集めており，Mn サイト を他の遷移金属イオンで置換した化合物の物性について 盛んに研究が行われている.これまでの研究から，置換す る遷移金属イオンの種類によって母体物質に与える影繁 が大きく異なることが分かってきたが, 不純物イオンが母 体物質の物性変化に与える影整についての詳しい㦈論は まだない ${ }^{(1-5)}$.

$\mathrm{Mn}$ サイトを $\mathrm{Cr}$ イオンで圆換した LaMn1-xCrxO3 1950 年代に G. H. Jonkerによって強磁性体であることが発見さ れた ${ }^{6)}$. Jonker はその強磁性発現機棈について，暧移金属 間に做く超交換相互作用が $\mathrm{Mn}^{3+}-\mathrm{Mn}^{3+}$ 間を強磁性的, $\mathrm{Mn}^{3+}-\mathrm{Cr}^{3+}$ 間を強磁性的, $\mathrm{Cr}^{3+}-\mathrm{Cr}^{3+}$ 間を反強磁性的と考える ことで説明できるとしている.我々は $\mathrm{LaMn}_{1-\mathrm{x}} \mathrm{Crx}_{3}$ につい て Mnイオンのみが強磁性に関与し, $\mathrm{Cr}$ イオンは磁化方向 の磁気モーメントを持たないことを見い出した ${ }^{7) .8) . ~ し か ~}$ しながら Jonker のモデルではこの実虽事実を説明できず, これらの物質の磁性を理解するためには新しいモテルの 考案が必要である。

一般に異種原子間に倒く超交換相互作用の符号につい ては, Goodenough-Kanamori 則という一般則があるものの， この符号を実験的に求めるのは非常に困難である. ランダ
ムに眍置した 2 元系の物質では同種原子間, 異種原子間の 交換相互作用が競合してしまうためである.

最近の研究で, $\mathrm{LaCrO}_{3}$ と $\mathrm{LaFeO}_{3}$ の単原子首ごとの超格 子を作製し，その面方位の違いによる磁気秩序の違いを見 ることで $\mathrm{Cr}^{3+}$ と $\mathrm{Fe}^{3+}$ 間の超交換相互作用が強磁性的である ことが実弱的に睍测された ${ }^{9 !}$.この研究では超格子を原子 層レベルで制御して作製することで規則的に配置させて 異種原子間の超交換相互作用の符号を決定しているが, 実 験的に非常に困藉である.

そこで本研究では実験結果とモデル計算を組み合わせ て行うことて $\mathrm{Mn}^{3+}$ と $\mathrm{Cr}^{3+}$ 間に伤く超交換相互作用の符号 を見皘もること，および Cr が磁化方向に磁気モーメント を持たないという実験結果を説明できるモデルを考案す ることを目的として研究を行った.

\section{2. 林篮方法}

モテル計算はモンテカルロ法により 2 元系の 3 次元 1 ジング模型で行った. LaMni-xCrxO3については, 実験結果 から絶緑体で局在スピンを持つ系であることが分かって いる.このことから磁性イオン間の交換相互作用は超交換 相互作用が支配的であると考えられる.すなわちスピン八 ミルトニアンはハイゼンベルグ模型で記述することがで きると考えられる．寒際の系に近づけるためには，本来八 イゼンベルグ模型で計算を行うのが望ましいと思われる が, 計算が非常に困難になるため, 今回はイジング模型を 採用して計算を行った

式（1）にイジング模型のハミルトニアンを示す.

$$
H=-2 \sum_{<i, j>} J_{i, j} S_{i}^{z} S_{j}^{z}-g \mu H \sum_{i} S_{i}^{z} .
$$

第一項は遇移金属原子間の超交換相互作用による項，第 二項は外部磁場による項である. 以下で, $\mathrm{Mn}^{3+}-\mathrm{Mn}^{3+}$ 間に

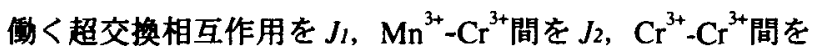
J とする.

ある 1 つのイオンのスピンに注目し, そのスピンを反転 させたときとそのままの状態を保ったときのエネルギー を計算し，エネルギーの低い状態にスピンを反転させる， という操作を絽り返して計算を行った，最初に格子点に 
$\mathrm{Cr}$ のドープ量に応じて $\mathrm{Mn}$ イオンと $\mathrm{C}$ 个オン，およびそ のスピンの向きをランダムに配置し, 上記のスピン反転の 操作を綝り返して，その系の基底状態での安定なスピン配 置を求めた.

格子のモデルとしては，実際の系に近づけるために Fig. 1 に示すようなz軸方向に伸びた 3 次元立方格子を用いた. $\mathrm{z}$ 軸方向に伸びていることを, 面内と面間に伤く超交換相 互作用の大きさを変えることで表した，具体的には，面内 に働く超交換相互作用 $\left(J_{\|}\right)$を面間 $\left(J_{\perp}\right)$ の 4 倍として計 算を行った $\left(J_{\| /}=4 J_{\perp}\right){ }^{10)}$. 格子のサイズは, 一辺あたりの 原子数を 20 とし $(\mathrm{L}=20 \times 20 \times 20)$, 周期的境界条件を用い て計算を行った

本研究の目的は $\mathrm{Mn}^{3+}-\mathrm{Cr}^{3+}$ 間に伤 $<$ 超交換 相互作用の符号を見積もり， 実験結果を説明するモデル を考案することである. そ こで, $J_{1}, J_{2}, J_{3}$ の大きさを 変化させたときの, 系の基 底状態での安定なスピン配 置の変化を钼測した．系の スピンの状態を表す指標と して，全体の磁化

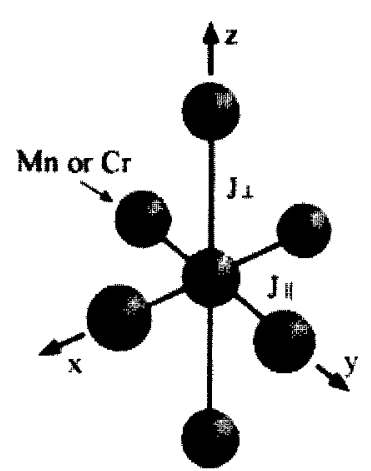

Fig. 1 Lattice model $<S z>$ Total, Mnイオンの磁気モーメントの平均值 $<S_{z}>M n$, $\mathrm{Cr}$ イオンの磁気モーメントの平均値 $\left\langle S_{z}>C r\right.$ を求め, 実験 結果との比較を行った.

計算のパラメーターとしては, 超交換相互作用 $J l, J 2$, $J_{3}$ と外部磁場 $\mathrm{H}$ があるが, $J_{1}$ で他のパラメーターを規格化 し, パラメーターの数を減らして計算を行った. 具体的に は, $J_{l}=1.0$ として固定し $J_{2} / J_{I}$ と $J_{3} / J_{1}$ を+10 から-10まで 変化させた. 外部磁場は $H / J_{I}=0.01$ に固定した.この $H / J_{l}=0.01$ という值は磁性イオン間の交換相互作用を考元 た場合に，通常の磁場（1 テスラ）よりも2析程度大きく 試料の磁化を飽和させるのに十分な磁場である. また、 イ オン, スピンの初期配置の違いによる影䡤を小さくするた めに同じパラメーターでの計算を各 5 回行い，磁化の值は その平均値を求めた。

\section{3. 什算結果およひ孝璂}

Fig. 2 にCrのドープ量 $\mathrm{x}=0.2$ として計算した磁化の相図 を示す. 磁化の值は $\mu_{B}$ 単位で格子点ひとつあたりの平均値 を取っている. 磁場方向を量子化軸とし, 磁場に平行にス ピンが揃っているときを+とし，磁場と反平行のときを一 と定義している.

今回の計算では最初にイオンの種類 $(\mathrm{Mn}, \mathrm{Cr})$ とその スピンの向きをランダムに配膡しているため, 計算の初期 状態においては $<$ Sz $>$ total $=<S z>M n=<S z>C r=0$ である. また，隣接するイオンの組み合わせとしては Cr のドープ
量 $\mathrm{x}=0.2$ の場合, $\mathrm{Mn}-\mathrm{Mn}$ ，または $\mathrm{Mn} \cdot \mathrm{Cr}$ が支配的である． $J_{2} / J_{1}=J_{3} / J_{1}=1$,すなわ $J_{1}=J_{2}=J_{3}$ の場合は, 系は 1 元系の 3 次元イジング模型と等価であり, 計算結果も $<S z>M n=4$, $<S z>C r=3$ となり完全な強磁性状態となっている. また, $\mathrm{Cr}$ 同士が隣り合う確率が小さく $J_{3}$ の影雷が小さいため, $J_{3} / J_{1}$ の值は 1 からずれても系全体の状態は大きくは変化 しない.しかし，J2/J1 の值が 1 からずれると， $J_{2} / J_{1}$ が正 の領域であっても $<\mathrm{Sz}>M n$ も $<\mathrm{S} z \mathrm{Cr}$ も小さな值をとって しまい，完全な強磁性状態になっていない。これはスピン 反転の操作を絽り返していくうちに系がエネルギーの極 小値を取ってしまうためであると考えられる.

$J_{1}, J_{2}, J_{3}$ がすべて正であるからエネルギー的に最も安 定になるのは完全な強磁性状態となった時であるが, 例え ば $J_{2} / J_{1}$ が大きい場合を考えると, $\mathrm{Mn} \cdot \mathrm{Cr}$ 間の交換相互作 用が大きいため, $\mathrm{Mn}$ と $\mathrm{Cr}$ が $\mathrm{xy}$ 面内で隣接する場合 $\mathrm{Mn} \cdot \mathrm{Cr}$ の交換相互作用が支配的となり，スピン反転の操 作を行うとその $\mathrm{Mn}$ と $\mathrm{Cr}$ のスピンが同じ方向を向くよう にスピンは反転する. 計算中にスピンが反転していく様子 を観測すると，初期状態でスピンが磁場と反対方向に向い た Crイオンと xy 面内で隣接する Mnイオンは, Crイオ ンのスピンと向きを揃えようとするため，磁場と反対方向 に向いていく，反転操作を絽り返すうちに周囲の Mn イオ ンのスピンが磁場と反对方向に向いてしまうと，その $\mathrm{Cr}$ イオンも磁場と反対方向を向いたままになる.この状態に おいては系はポテンシャルの谷の準安定状態にあり，外部 磁場がポテンシャルの山を越えられるほど十分に大きく ないため, 系は準安定状態で止まってしまい, 最も安定な 状態（完全強磁性状態）にはならない。この結果，Cr イ オンを核として磁場と反对方向にスピンが揃ったクラス ターができてしまい, $<S z>M n$ や $<z>C r$ が小さい值をと ってしまうと考えられる.

スピン間の交換相互作用が競合しあうスピングラス状 態においては, エネルギーが多谷構造をとり冷却過程の䕗 いなどにより系が異なる状態をとることがよく知られて いるが，今回の計算においても $J_{1}, J_{2}, J_{3}$ の差が大きい時 には同様な状況になっていると考えられる。

$J_{2} / J_{1}<0$ の時も， $J_{2} / J_{1}>0$ の時と同様に考えると, $J_{2} / J_{1}=$ -1 の時は Mn イオンは磁場方向にスピンの向きが揃い, $\mathrm{Cr}$ イオンは磁場と反対方向にスピンの向きが揃う. $J 3 / J_{1}$ の值が変わっても系全体の様子は大きくは変化しないが, $J_{2} / J_{1}$ の值がー1 からずれると Crイオンを核としてクラス ターが形成されるようになり， $<S z>M n ，<S z>C r$ ともに 值が0に近づくと考えられる.

また, $J_{2} / J_{1}=0$ のライン上では, $\mathrm{Mn}$ と $\mathrm{Cr}$ がほとんど独 立な系として振舞うため, 外部磁場の影掣で $<S z>M n$ も $<S z>C r$ も正の值をとると考えられるが，計算結果も $<S z>M n, \quad<S z>C r$ ともに正の值を示した.

実験結果から Cr イオンは磁化方向の磁気モーメントを 
持たないことが分かっているがこの実駼結果に対応する のは $<S z>C r$ が 0 となる場合である. $<S z>C r$ の相図を見る とそのような領域が, $J_{2} / J_{I}<0\left(\mathrm{Mn}^{3+}-\mathrm{Cr}^{3+}\right.$ : 反強磁性) の 場合のみ存在しており, $J_{2} / J_{1}>0\left(\mathrm{Mn}^{3+}-\mathrm{Cr}^{3+}\right.$ : 強磁性) の 領域には存在しないことが分かる. Cr のドープ量を変え て（x=0.1，x=0.33）計算した結果についても， $\left\langle S_{z}>C r\right.$ が 0 となる領域は $J_{2} / J_{I}<0\left(\mathrm{Mn}^{3+}-\mathrm{Cr}^{3+}\right.$ ：反強磁性）にしか存 在しなかった.すなおち，Cr が磁化方向の磁気モーメン 卜を持たないということは $\mathrm{Mn}^{3+}-\mathrm{Cr}^{3++}$ 間の超交換相互作用 が反強磁性的であることを示唆している. また， $\langle S z>M n$ は全ての領域で正の値を示し磁化を持っている.

$<S z>C r=0$ が $J_{3} / J_{1}$ の值に関係なく $J_{2} / J_{1}<-1$ の広い領域

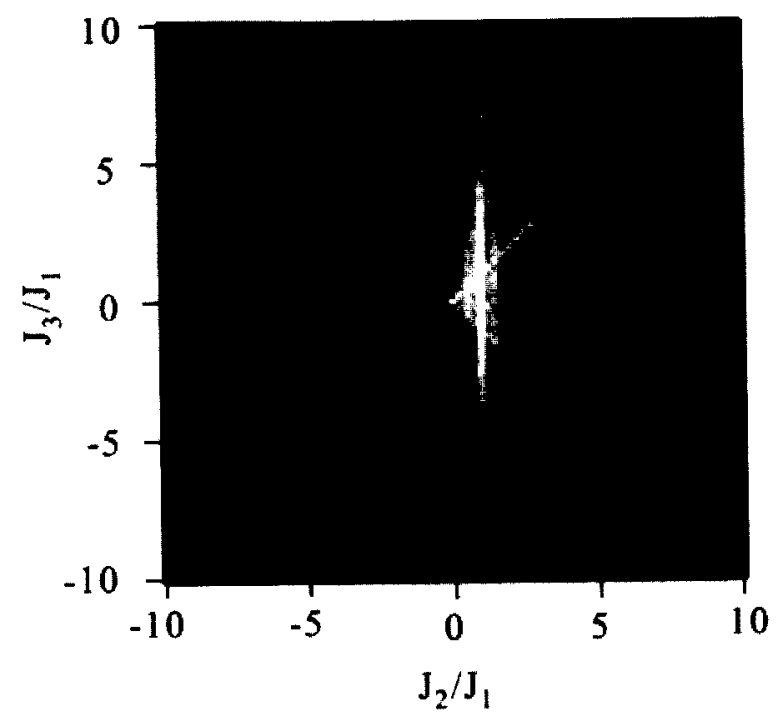

で得られていることから， $<S z>C r=0$ となるのは $\mathrm{Cr}-\mathrm{Cr}$ 間 の反強磁性的交換相互作用のためではなく，Cr イオンを 核としたクラスター形成にあると考えている.

また, $\mathrm{Cr}^{3+}-\mathrm{Cr}^{3+}$ 間の超交換相互作用については $\mathrm{x}=1.0$ の化 合物 $\mathrm{LaCrO}_{3}$ において隣り合う $\mathrm{Cr}$ イオンのスピンがすべて 反強磁性的に整列する G-type の反強磁性体であることか ら反強磁性的と考えられる。.また今回の計算では $\mathrm{Mn}^{3+}-\mathrm{Mn}^{3+}$ 間の超交換相互作用は，強磁性的であると考え て計算を行った．母体化合物 $\mathrm{LaMnO}_{3}$ は，軌道が整列する ことで面内で強磁性的, 面間で反強磁性的にスピンが揃う， A-type の反強磁性体であるが，我々は $J l$ をー 1 として計算 を行ったところ, 全体の磁化が 0 となってしまい, 強磁性

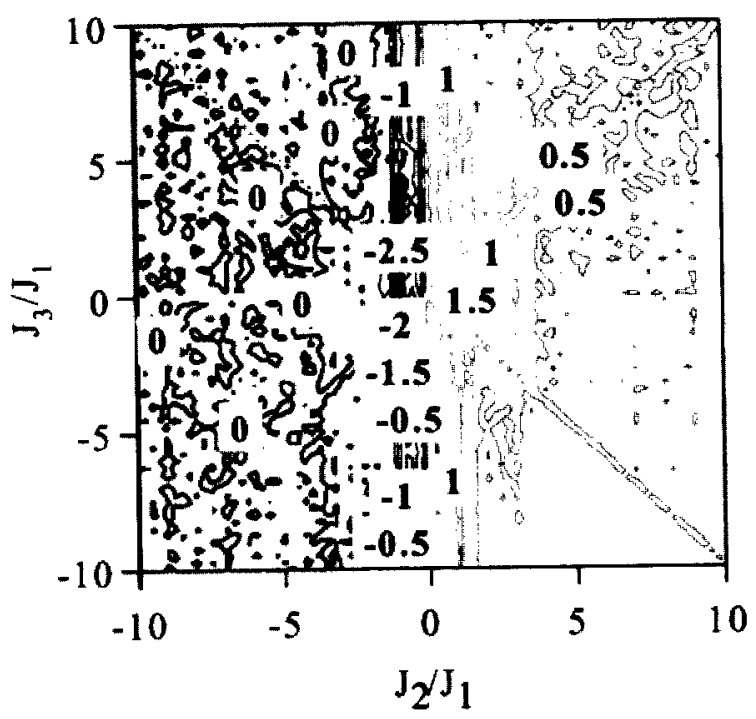

(a) Cr magnetization
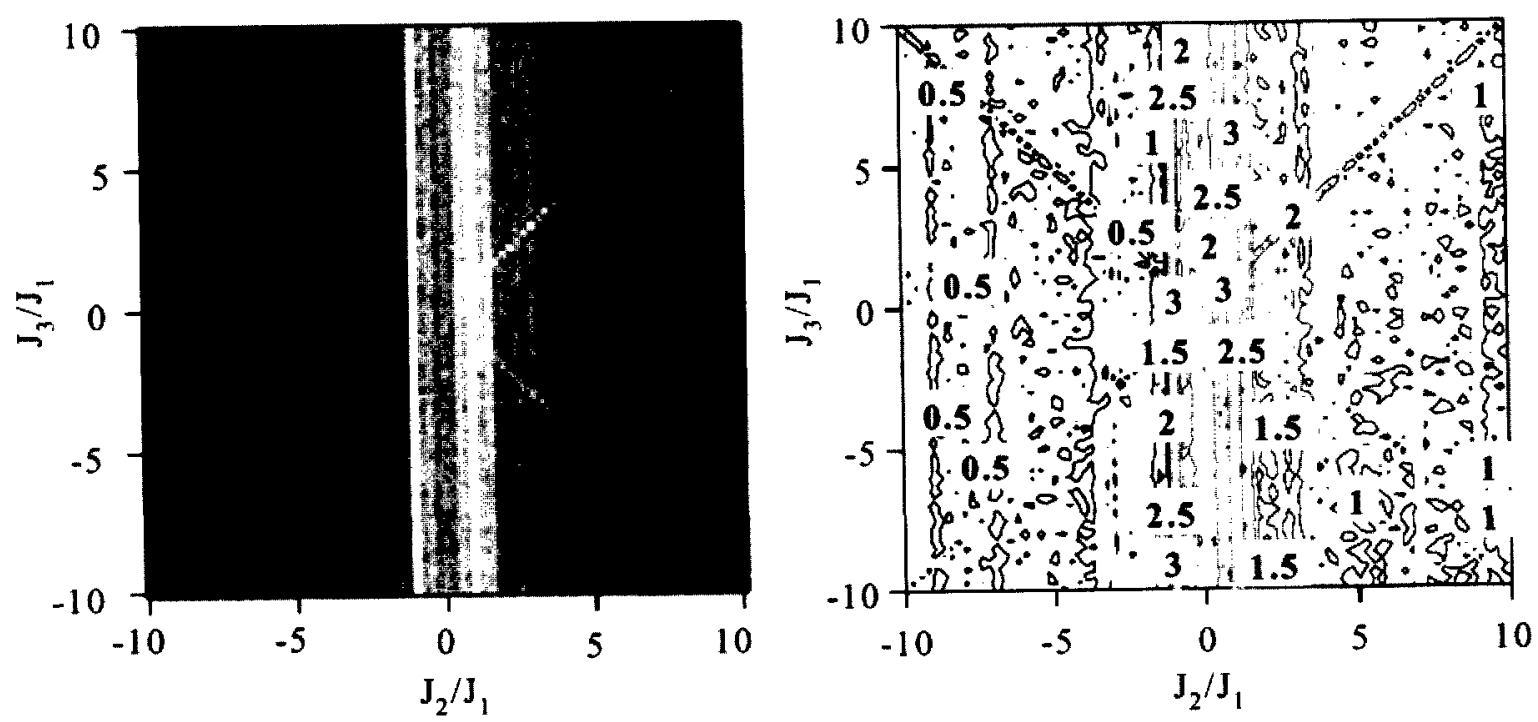

(b) Mn magnetization

Fig. 2 Magnetization phase diagrams obtained from Monte Carlo calculation based on the 3D Ising model for $\mathrm{LaMn}_{1-\mathrm{x}} \mathrm{Cr}_{\mathrm{x}} \mathrm{O}_{3}: \mathrm{x}$ 0.20. (a) Magnetization noting only $\mathrm{Cr}$ atoms. (b) Magnetization noting only $\mathrm{Mn}$ atoms.

In the left-hand side figures, white parts show the spin aligned parallel to the external magnetic field, and black parts show the spin anti-parallel to the external magnetic field. The right hand side figures show the values of the magnetization in $\mu_{B}$. 
が発現する領域が存在しなかった。このことから， $\mathrm{Mn}^{3+}-\mathrm{Mn}^{3+}$ を強磁性的と考えるのは妥当であると思われる すなわち, $\mathrm{Mn}^{3+}-\mathrm{Mn}^{3+}$ を強磁性, $\mathrm{Mn}^{3+}-\mathrm{Cr}^{3+}$ を反強磁性, $\mathrm{Cr}^{3+}-\mathrm{Cr}^{3+}$ を反強磁性と考えることで $\mathrm{Cr}$ が磁化方向に磁気モ 一メントを持たないという実験結果を説明できる.

しかし，実䥐結果の枹和磁化の值と比較すると，全体の 磁化の計算結果は実験値よりも小さな值をとる.これにつ いては，格子サイズをもっと大きくすることやハイゼンべ ルグ模型での計算を行うなど、より現実の系に近づけるこ とによって改善できると考えている.

$\mathrm{Mn}^{3+}-\mathrm{Cr}^{3+}$ 間の超交換相互作用が反強磁性的であるとい う結果は Kanamori-Goodenough 則と一致しない.この原因 としては，酸素を介した遷移金属イオン間の結合角， Mn-O-Crのなす角が $180^{\circ}$ からかなりずれているためだと 考えられる. 超交換相互作用は遷移金属原子之酸素原子之 の結合角が $90^{\circ}$ の時と $180^{\circ}$ の時では符号が反枟する. $\mathrm{Mn}^{3+}-\left(d^{4}\right)-\mathrm{O}^{2}-\mathrm{Cr}^{3+}\left(d^{3}\right)$ 間での超交換相互作用は, 結合角が $180^{\circ}$ の場合治磁性的だと考えられるが，結合角が $90^{\circ}$ の場合は反強磁性的だと考えられる. 結合角がこの中間に ある場合は強磁性的相互作用之反強磁性的相互作用の競 合が起こる. $\mathrm{LaMn}_{1 . \mathrm{x}} \mathrm{Cr}_{\mathrm{x}} \mathrm{O}_{3}$ においては反強磁性的相互作用 之強磁性的相互作用がちょうど競合しあう領域にあり，そ の結果反強磁性的な相互作用が現れている可能性がある と考えている.この $\mathrm{Mn}^{3+}-\mathrm{O}^{2-}-\mathrm{Cr}^{3+}$ 間に传く超交換相互作用 の符合については今後の研究が期待される.

\section{4. まとめ}

2 元系 3 次元イジング模型でモデル計算を行い,
$\mathrm{Mn}^{3+}-\mathrm{Mn}^{3+}, \mathrm{Mn}^{3+}-\mathrm{Cr}^{3+}, \mathrm{Cr}^{3+}-\mathrm{Cr}^{3+}$ 間に働<超交換相互作用 の大きさを変化させて磁化の挙動の変化を調べ, 実験結果 を説明するモテルを考案することを試みた. その結果, $\mathrm{Mn}^{3+}-\mathrm{Mn}^{3+}$ 間を強磁性, $\mathrm{Mn}^{3+}-\mathrm{Cr}^{3+}$ 間を反強磁性, $\mathrm{Cr}^{3+}-\mathrm{Cr}^{3+}$ 間を反強磁性という超交換相互作用を考えることで $\mathrm{Cr}$ 个 オンが磁化方向に磁気モーメントを持たないという実験 結果を再見することができた.

\section{文部}

1) F. Damay, A. Maignan, C. Martin, and B. Raveau, J. Appl. Phys., 82, 1485 (1997).

2) A. Maignan, F. Damay, C. Martin, and B. Raveau, Mater. Res. Bull., 32, 965 (1997).

3) A. Barnebe, A. Maignan, M. Hervieu, F. Damay, C. Martin, and B. Raveau, Appl. Phys. Let., 71, 3907 (1997).

4) Y. Moritomo, A. Machida, S. Mori, N. Yamamoto and A. Nakamura, Phys. Rev. B, 60, 9220 (1999).

5) F. Damay, C. Martin, A. Maignan M. Hervieu and B. Raveau, Appl. Phys. Lett., 73, 3772 (1998).

6) G. H. Jonker, Physica, 22, 707 (1956).

7) K. Ono, S. Nakazono, T. Kihara, S. Kawaguchi, Y. Nakamura, M. Miyayama, H. Fujioka, T. Koide, and M. Oshima, Physica B, in press

8）中園，小野，木原，宮山，尾嶋，日本応用磁気学会誌，印刷中

9) K. Ueda, H. Tabata, T. Kawai, Science, 280, 1064 (1998).

10) A. J. Millis, Phys. Rev. B, 55, 6405 (1997). 